\title{
Ditado Digital - A Inserção de Tecnologias Educacionais na Educação
}

\author{
Jessé Oliveira, Maelson M. de Lima, Alanna C. Coelho Monteiro, Eliane Brito de \\ Lima, Marx Magnus Silva Nóbrega
}

Departamento de Computação - Universidade Estadual da Paraíba (UEPB)

Rua Baraúnas, nº 351, CEP 58429-500, Bairro Universitário,

Campina Grande - PB - Brasil.

\author{
\{jesseh.oliv, marxmagnus\}@gmail.com, \\ \{alannacoelho, maellson\}@hotmail.com, eliabrito@ig.com.br
}

\begin{abstract}
The technological evolution and transformations in the productive world have instigated the various educational sectors to think about new ways of curriculum construction. Here we present the Ditado Digital, software designed to facilitate the process of teaching/learning of Portuguese discipline for students and teachers of the elementary school, allowing greater interaction between teacher and students. The software was developed for the web using PHP and database as MYSQL.
\end{abstract}

Resumo. A evolução tecnológica e as transformações no mundo produtivo têm instigado os diversos setores educacionais a refletirem sobre novos modos de construção curricular. Este artigo busca apresentar o Ditado Digital, um software que pretende facilitar o processo de ensino/aprendizagem da disciplina de Português para alunos e professores do Ensino Fundamental I, possibilitando uma maior interação entre o professor e os alunos. $O$ software foi desenvolvido para a web utilizando a linguagem PHP e banco de dados $M y S Q L$.

Palavras-Chaves: Ditado digital, Ensino/Aprendizagem, Tecnologia educacional.

\section{Introdução}

A evolução tecnológica e as transformações no mundo produtivo têm instigado os diversos setores educacionais a refletirem sobre novos modos de construção curricular. O curso de Licenciatura em Computação surge como um aporte essencial ao debate de construção do conhecimento escolar, visto que são inúmeras as possibilidades do uso computacional nesse processo.

O profissional licenciado em Computação constitui um profissional que compreende os fios psicossociais do processo ensino/aprendizagem. Ele une elementos técnicos, didáticos e pedagógicos capazes de potencializar a ação educativa.

Neste contexto, o Ditado Digital é um software educacional que tem como objetivo auxiliar professores de Língua Portuguesa, do Ensino Fundamental I, no acompanhamento do desempenho de seus alunos em relação à ortografia.

O presente software foi devidamente empregado em um intercâmbio entre as áreas de Educação e Computação, no sentido de oportunizar aos alunos-estagiários uma 
vivência pedagógica relacionada à Informática Educacional, experiência descrita no âmbito deste artigo.

Na próxima seção abordamos sobre a informática na educação escolar; na seção 3 abordamos sobre a Formação Docente: Identidade do Professor e Saberes Pedagógicos relacionados à inserção de tecnologias; na seção 4 falamos sobre o Ditado Digital e alguns trabalhos relacionados; na seção 5 falamos sobre o processo de desenvolvimento do Ditado Digital; na seção 6 temos a descrição e análise do software; e na seção 7 as considerações finais.

\section{Informática e Educação Escolar}

São diversos os efeitos sentidos pelos ambientes educacionais quando neles são inseridos os computadores. Há uma mudança profunda no paradigma pedagógico devido à possibilidade de diversificação dos métodos de ensino proporcionados pelos computadores quando estes são usados para melhorar a didática de ensino. [Valente 1993].

Existem diferentes opiniões, posicionamentos e ideias, relacionadas ao tema informática na educação, bem como as visões que dela surgem. "A introdução de uma nova tecnologia na sociedade provoca, naturalmente, uma das três posições: ceticismo, indiferença ou otimismo" [Valente 1993].

Há de se educar a comunidade escolar de forma a torná-la consciente de que a tecnologia está cada vez mais presente no dia-a-dia dos alunos, e que estes são atraídos pela novidade, pela facilidade de comunicação que a Internet nos dá, e é claro, pela grande interação que a maioria dos softwares educativos proporciona entre alunos/professores/máquinas.

Software educativo é um sistema computacional, intencionalmente concebido para facilitar o processo de aprendizagem de conceitos específicos [Gomes e Padovani 2005]. O software educacional possui características específicas que devem ser levadas em consideração na hora de se pensar num processo para o seu desenvolvimento de forma que atenda às suas necessidades básicas como: colaborar com o processo de ensino/aprendizagem, melhorar as formas de comunicação entre professor/aluno e possibilitar a construção de conteúdos [Lima 2012].

Embora existam fatores que dificultam a inclusão de softwares educacionais no sistema de ensino, existem também diversos outros fatores favoráveis que mostram a sua importância no processo de ensino/aprendizagem, estimulando o desenvolvimento de uma consciência crítica por parte dos alunos.

\section{Formação Docente: Identidade do Professor e Saberes Pedagógicos relacionados à inserção de tecnologias}

Para ensinar é necessário ao professor compreender todo o universo ao seu redor de forma que já tenha construído a sua identidade de professor. Ele precisa se adaptar às culturas e linguagens diferentes de seus campos específicos. Conforme Pimenta (2008) percebe-se a necessidade dos futuros professores enfrentarem o desafio de conviver (falar e ouvir) com linguagens e saberes diferentes daqueles de seus campos específicos; o que nos parece essencial para o trabalho interdisciplinar e coletivo nas escolas. 
É papel da comunidade escolar, formar não apenas profissionais, mas, cidadãos capazes de se adaptarem a qualquer cultura ou linguagem, convivendo com a diversidade cultural, de forma que a comunidade escolar se relacione com a sociedade ao seu redor e tente entendê-la, para assim ajudá-la a melhorar. Neste sentido Pimenta aborda:

\begin{abstract}
A educação escolar, por sua vez, está assentada fundamentalmente no trabalho dos professores e dos alunos, cuja finalidade é contribuir com o processo de humanização de ambos pelo trabalho coletivo e interdisciplinar destes com o conhecimento, numa perspectiva de inserção social, crítica e transformadora. [Pimenta 2008. p.23].
\end{abstract}

Uma grande vantagem que o uso dos computadores nos proporciona é a descoberta de novos conhecimentos, porém muitas vezes esses conhecimentos não são corretos e outra vez nos deparamos com mais uma prova de que a máquina não substituirá o professor em sala de aula e que falta muito para um software educacional, sozinho, conseguir alcançar o nível de maturidade que o faça ter o mesmo desempenho de uma aula presencial com o professor.

Seguindo essa linha de pensamento, vemos o caso da Internet e de como ela está sendo usada para a pesquisa. Segundo [Freire 1996] "Não há ensino sem pesquisa nem pesquisa sem ensino". Não só o professor, mas também os alunos necessitam aprender a pesquisar e com isso poderá também distribuir conhecimentos verídicos e confiáveis. Com o uso dessa nova ferramenta as possibilidades de aprendizagem se multiplicam constantemente e o professor acaba se beneficiando de uma forma muito prazerosa de ensinar.

\title{
4. O Ditado Digital
}

Segundo [Valente 1993], os softwares educacionais são classificados de acordo com a maneira como o conhecimento é manipulado. Seguindo esta linha, o Ditado Digital classifica-se como um jogo educativo, por apresentar componentes lúdicos para o entretenimento dos usuários.

O Ditado Digital é um software educacional web, que tem como objetivo auxiliar professores de Língua Portuguesa, do Ensino Fundamental I, no processo de ensino/aprendizagem, além de facilitar a dinamicidade das aulas e aumentar a interação entre professores e alunos. É um software de exercício e prática composto de material multimídia, que dita uma palavra, a qual está associada a uma imagem para facilitar a assimilação da escrita por parte do aluno, e assim, possa escrevê-la de forma correta. $\mathrm{O}$ programa gera ainda relatórios e gráficos para o professor, permitindo que este tenha total conhecimento sobre as dificuldades e facilidades que o aluno ou uma turma tem sobre determinada palavra ou até sobre uma atividade já realizada. O Ditado Digital foi desenvolvido por alunos curso de Licenciatura em Computação da Universidade Estadual da Paraíba, em uma das disciplinas do curso, com o auxílio de professores especialistas na área de Interação Humano-Computador-IHC, Engenharia de Software, Bando de Dados e Pedagogos.

\subsection{Trabalhos Relacionados}

O Ditado Digital é um software educacional, composto de material multimídia e tem como base a Teoria Cognitiva da Aprendizagem Multimídia de Richard Mayer (2003). 
O processo de aprendizagem ou de cognição do ser humano é baseado num sistema de memórias, em que uma informação precisa ser processada, analisada e assim, armazenada, para que, quando necessário, haja uma fácil recuperação do seu conteúdo.

O ser humano possui três formas distintas de memórias para auxiliá-lo no processo cognitivo, que são: memória sensorial, memória de curto prazo e memória de longo prazo [Mayer 2004].

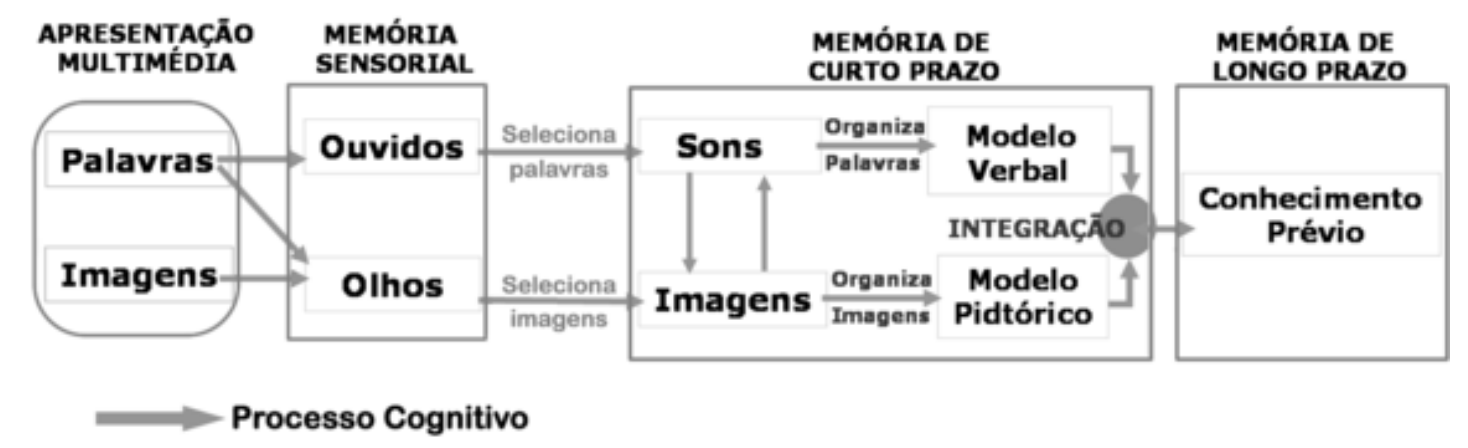

Figura 1. Processamento de informação [Mayer 2003]

Na Figura 1, Richard Mayer revela como imagens e palavras são assimiladas através de uma apresentação multimídia entrando na memória sensorial através da audição e visão. Este modelo mostra que a nossa memória organiza os sons e as imagens de forma relacional e os integra para mandar para a memória de longo prazo, o que constitui o processo de ensino/aprendizagem.

Mayer comprova que o uso de imagens e sons relacionados facilita o processo de busca por um "registro" ou informação no cérebro. O som ou a imagem remete ao seu significado ou a algum fato que esteja a este(a) relacionado.

[Giraffa, Marczak e Prikladnicki 2005] abordam sobre o processo de desenvolvimento de um software educacional explicitando algumas características específicas desta categoria de software.

[Kam et. al. 2008] propõe um processo de desenvolvimento que pode ser modelado para o design de interfaces de jogos educacionais, expondo todas as fases que compreenderam o processo de produção de jogos educacionais para crianças na Índia.

[Pizzol e Zannata 2001] expõe o RPG como técnica para a construção de software educacional, baseado nos conceitos de jogos eletrônicos e aplicações web empregados de forma lúdica ao ensino.

A metodologia de pesquisa utilizada neste artigo foi baseada em [Lima 2012] que aborda sobre a importância do desenvolvimento de softwares educacionais bem como das formas que devem ser realizadas pesquisas na área, servindo como aporte para o estudo desta categoria de software.

\section{Processo de Desenvolvimento do Ditado Digital}

O Ditado Digital foi desenvolvido com base nos conceitos de interface do usuário, vistos pelo lado da Interação Humano-Computador-IHC, disciplina que estuda o processo interativo entre os seres humanos (homem) e as máquinas (dispositivos) durante a realização de uma tarefa [Benyon 2011]. 
Inicialmente foi desenvolvido uma pré-interface funcional do sistema pela equipe de design juntamente com desenvolvedores (alunos), baseado nos requisitos levantados pela equipe de análise (auxiliada pelo professor de Engenharia de Software) com o Professor de Interface. Esta interface inicial funcionou como um protótipo, que abrangia certos requisitos que foram considerados essenciais pela equipe de análise. Este protótipo foi levado para um teste com os professores e alunos do curso de Pedagogia, voluntários da própria Universidade.

O protótipo foi desconsiderado e as principais adaptações sugeridas pelo cliente/usuário a respeito do protótipo foram captadas. Com este feedback a equipe começou a planejar a modelagem do banco de dados, além de uma previsão para o tempo de desenvolvimento do projeto.

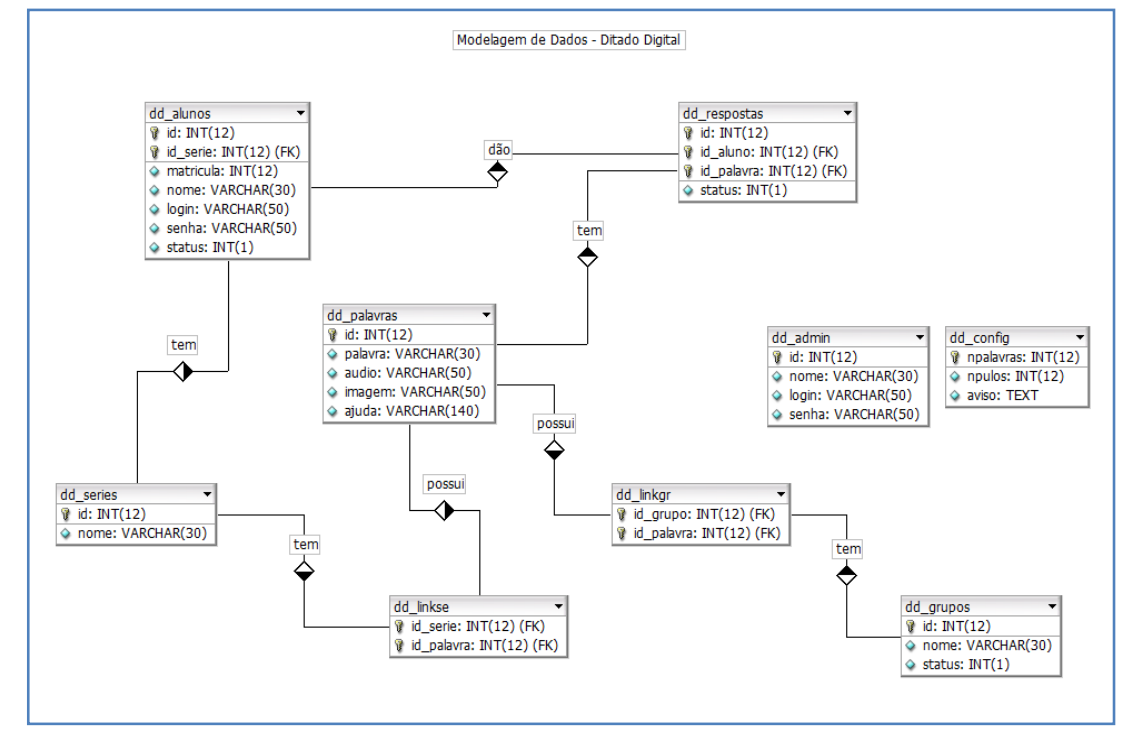

Figura 2. Modelagem do banco de dados

A Figura 2 mostra o modelo conceitual do Ditado Digital que é representado através de um diagrama, chamado Modelo de Entidade Relacionamento (MER). A partir desse modelo a equipe de desenvolvimento iniciou o processo de codificação e produção das telas do software.

Por se tratar de um software para a web, a linguagem de programação adotada para o desenvolvimento foi o PHP (Hypertext Preprocessor), uma linguagem interpretada, livre e amplamente utilizada em conjunto com o MySQL, um banco de dados leve e gratuito.

Outras linguagens como o HTML, XML, CSS, JavaScript, e algumas bibliotecas tais como: jQuery, FPDF, WideImage e Soundmanager, foram utilizadas em conjunto para produzir o Ditado Digital.

\section{Descrição e Análise do Ditado Digital}

O Ditado Digital foi dividido em duas áreas: uma específica para o aluno, no qual o software oferece subsídios que auxiliam na compreensão e assimilação das palavras, através de recursos audiovisuais. E outra para o professor, o qual age como mediador do processo de aprendizagem, bem como administrador do software. Nesta condição, ele 
tem acesso a relatórios detalhados, que possibilitam o monitoramento de uma ou várias séries ou até mesmo de um aluno específico.

\section{1. Área do Aluno}

Ao entrar no sistema e iniciar o ditado, o aluno ouvirá a pronúncia de uma palavra, ver uma imagem correspondente e ainda um texto de ajuda, que pode ser a definição da palavra ou uma frase que o ajude a lembrar a escrita. No final, o sistema gera um relatório para o aluno, informando o número de questões que ele acertou, que errou, o percentual de acerto e ainda lhe dá a possibilidade de salvá-lo em PDF. As Figuras 3 e 4 mostram a visão do aluno na tela do Ditado e a tela de Resultados, exibida ao término da atividade.

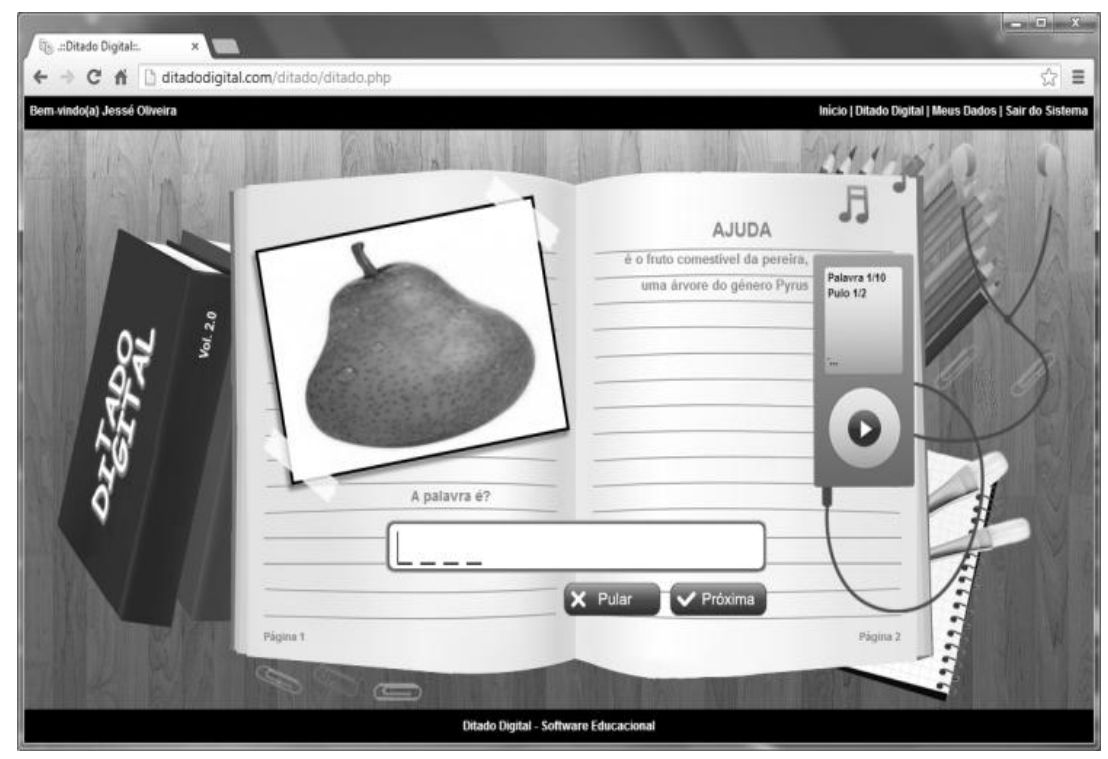

Figura 3. Área do aluno no Ditado Digital - preenchimento de palavras

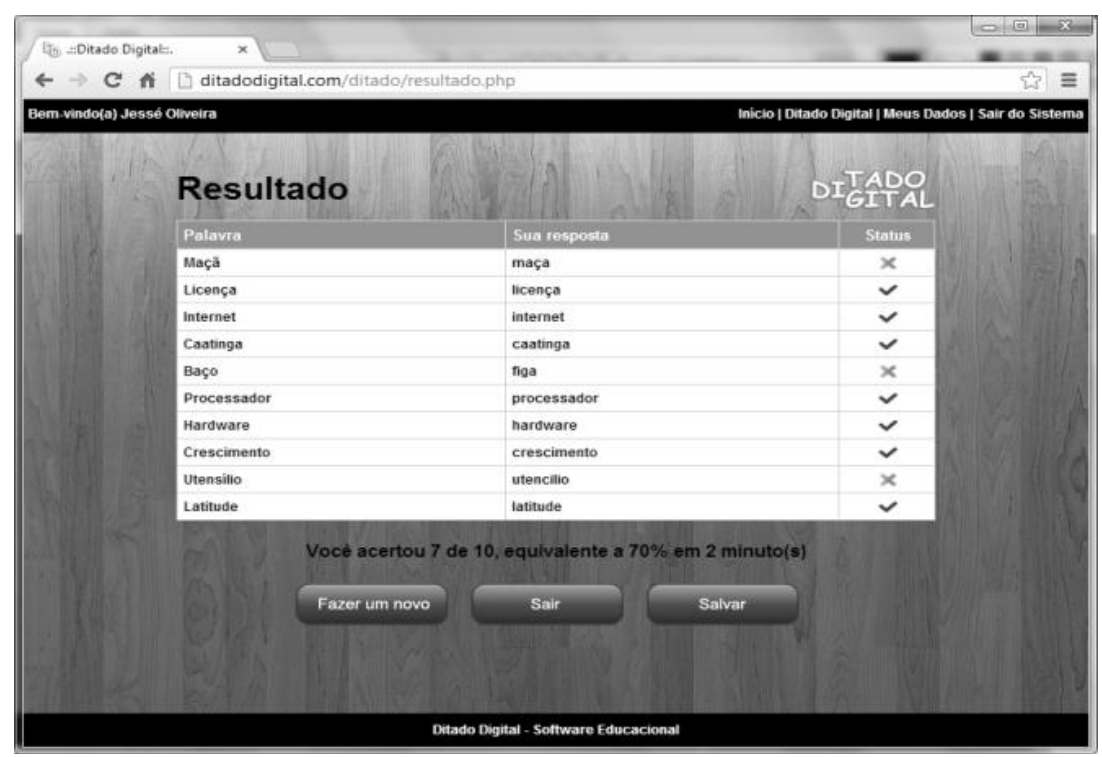

Figura 4. Área do aluno no Ditado Digital - tela de respostas 
Na tela do Ditado Digital, é permitido ao aluno ouvir quantas vezes for necessário o áudio da palavra, assim, se em um primeiro momento o aluno não compreender a pronúncia, poderá repeti-la, até que a compreenda.

Há possibilidade de solicitar uma nova palavra quando não compreendeu ou não sabe escrever a palavra atual (o número de "pulos" permitidos é definido pelo professor na área de administração); bem como visualizar de quantas palavras será o ditado e em que palavra o aluno se encontra.

A área do aluno oferece ainda, a possibilidade de editar seus dados cadastrais, como nome, login e senha (dados como matrícula e série não são permitidos a edição). Utiliza sistema randômico de busca de palavras, ou seja, de ordem aleatória, que evita a memorização de sequência de palavras.

\section{2. Área do Professor}

O software conta com uma área de administração, que permite ao professor ter total controle sobre os alunos cadastrados, relatórios e definir a quantidade de palavras do ditado. Além disso, o professor pode cadastrar suas próprias palavras, bem como classificá-las em grupos/temas e vários outros recursos disponíveis no software. As Figuras 5 e 6 ilustram a visão do professor ao acessar o sistema administrativo do Ditado Digital.

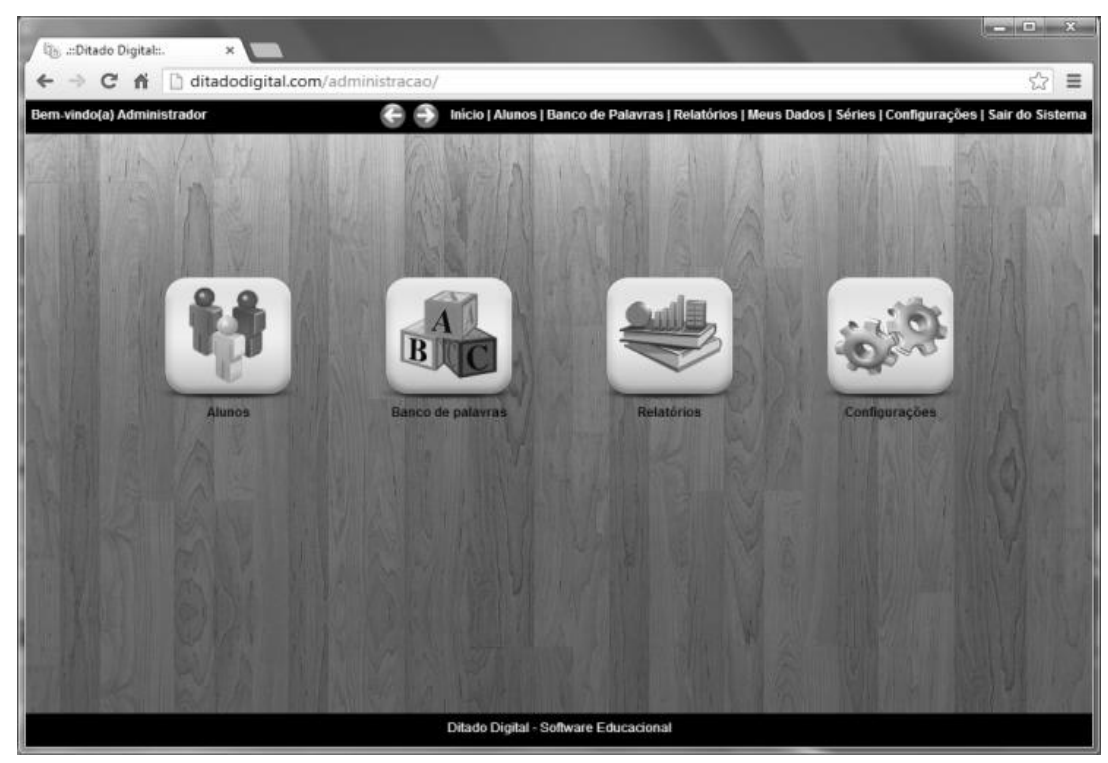

Figura 5. Área administrativa do professor 


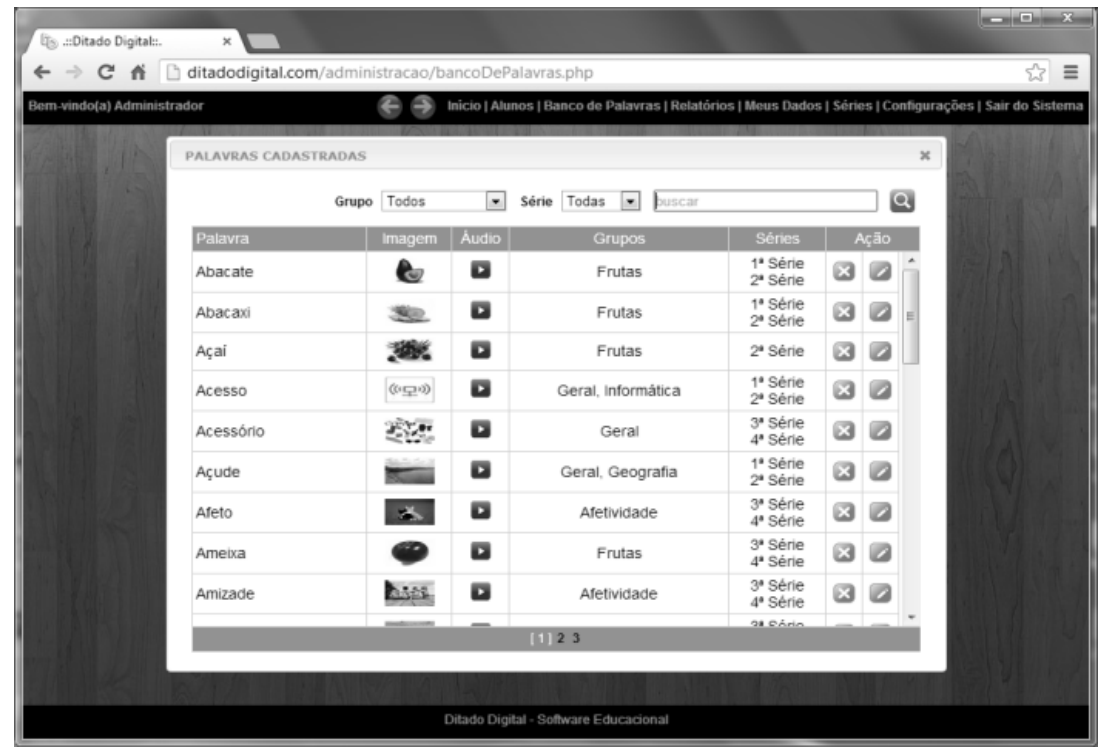

Figura 6. Área administrativa para controle de imagens e sons inseridos

O sistema permite ainda ao professor o monitoramento das séries ou até mesmo de um aluno específico, tudo isso por meio dos relatórios gerados, os quais, através de uma combinação de variáveis, possibilita extrair resultados relevantes ao professor.

Os relatórios são exibidos em gráficos, estes selecionados pelo professor, os quais podem ter a forma de pizza, pizza 3D, barras, colunas, colunas 3D, etc. A Figura 7 mostra um dos relatórios gerados, o qual exibe as palavras nas quais os alunos tiveram maior dificuldade de escrita.

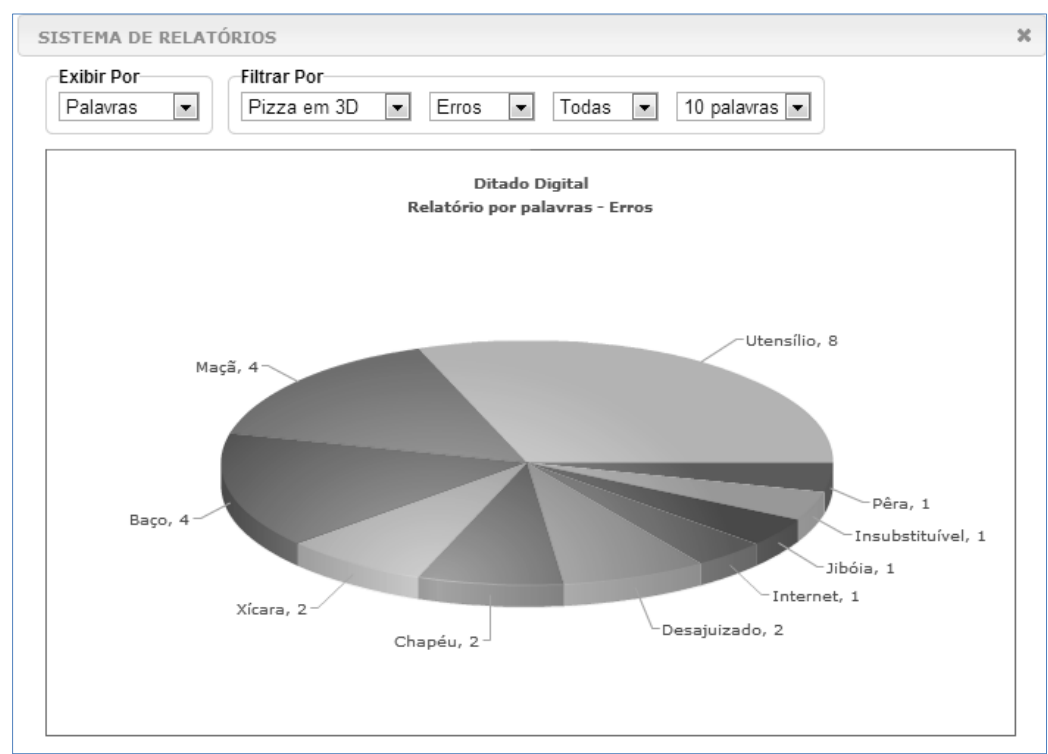

Figura 7. Relatório por palavras - Erros

A área administrativa oferece ainda a possibilidade de: bloquear/desbloquear alunos ao acesso do sistema; filtrar alunos por série, status ou palavras-chave; cadastrar palavras para um ou mais grupos/séries; buscar uma palavra específica por grupo, série ou palavra-chave; cadastrar séries, grupos/temas; determinar a quantidade de palavras do ditado e o número de "pulos" e gerar relatórios com uma combinação de variáveis. 


\section{Considerações finais}

A produção do Ditado Digital como software educacional contribuiu para a formação de um senso crítico a respeito da necessidade da inserção da tecnologia em sala de aula. Serviu também para entender qual a visão dos professores em relação a essas novas tecnologias apresentadas.

A utilização do software no período de estágio favoreceu a oportunidade de testes e ajustes necessários ao mesmo, a partir da percepção e contribuição dos professores do curso de Pedagogia, que destacaram a importância do Ditado Digital como instrumento mediador da aprendizagem.

Em síntese, destacamos o quanto a computação pode ajudar no processo de ensino/aprendizagem e como esse processo de inserção da tecnologia no meio educacional pode ser aplicado. Buscamos evidenciar a necessidade de investimento na capacitação de professores, no incentivo ao desenvolvimento de softwares educacionais e na conscientização da sociedade, que precisa ser envolvida no processo.

\section{Referências}

Benyon, D. (2010). Interação Humano-Computador. Ed. Pearson.

Cox, Kenia Kodel. Informática na Educação Escolar. Campinas, SP: Autores Associados, 2003 (coleção do nosso tempo, 87).

Cybis, W., Betiol, A.H., Faust, R. (2010). Ergonomia e Usabilidade. Ed. Novatec.

Freire, Paulo. Pedagogia da Autonomia. São Paulo: Paz e Terra, 1996.

Giraffa, L., Marczak, S., e Prikladnicki, R. (2005) "PDS-E: Em direção a um processo para desenvolvimento de Software Educacional" In SBIE.

Gomes, A. S.; Padovani, S. (2005) "Usabilidade no ciclo de desenvolvimento de software educativo". In: SBIE Simpósio Brasileiro de Informática na Educação, Juiz de Fora (MG).

Lima, M. M.; Lima, A. R.; Monteiro, A. C. C.; Cavalcante Júnior, E. H.; Gomes, L. Q. L. (2012) "Uma Revisão Sistemática da Literatura dos Processos de Desenvolvimento de Software Educativo". In: XXIII SBIE Simpósio Brasileiro de Informática na Educação, Rio de Janeiro (RJ).

Lucena, M. (2002) "Diretrizes para a Capacitação do Professor na Área de Tecnologia Educacional: Critérios para a Avaliação de Software Educacional". Disponível em: <ftp://vpn.fpte.br/cursos/Pos_Tecnologia_Educacional_T1/Aula_080510_Prof_Leon idesJustiniano/Crit_rios\%20avalia_o\%20software\%20educacional.pdf $>$, Acessado em agosto de 2013.

Marczak, S., Giraffa, L., Almeida, G., e Blois, M. (2003) "Modelando um ambiente de aprendizagem na Web: a importância da formalização do processo de desenvolvimento" In: SBIE.

Pimenta, Selma Garrido. Formação de professores: identidade e saberes da docência. In: . PIMENTA, Selma Garrido (org.). Saberes pedagógicos e atividade docente. 6 ed. São Paulo: Cortez, 2008. 
Pizzol Dal, Cassiano; Zanatta, Alexandre Lazaretti; "O RPG como técnica na construção de software educacional: A Revolução Farroupilha.” In: SBIE 2001.

Rangel, V. G.; Cury, D.; e Menezes, C. S. (2011)."VCom: Uma Abordagem para Modelagem de Ambientes Colaborativos para Apoiar a Aprendizagem". In: XXII SBIE - XVII WIE.

Mayer, Richard. The promise of multimedia learning: using the same instructional design methods across different media. Learning and Instruction 13 (2003), 125-139, Pergamon.

Mayer,R.,Moreno,R. (2003). "Nine Ways to Reduce Cognitive Load in Multimedia Learning”, Universidade Califórnia, Universidade Novo México.

Mayer, R.; Fennell, Sherry; Farmer, Lindsay; Campbell, Julie; (2004). "A Personalization Effect in Multimedia Learning: Students Learn Better", disponível em http://tecfa.unige.ch/tecfa/teaching/methodo/Mayer2004.pdf

Valente, José Armando. Por que o computador na educação? Disponível em: http://www.ich.pucminas.br/pged/db/wq/wq1_LE/local/txtie9doc.pdf. 